\title{
La educación básica en Santa Tecla, El Salvador durante la década de 1930
}

\author{
Carlos Ernesto Cortez Tejada ${ }^{1}$
}

Recibido en marzo de 2015, aceptado en abril de 2015.

\begin{abstract}
Resumen
Este trabajo es una investigación a partir de fuentes orales, e indaga sobre la educación en Santa Tecla, en la década de 1930. Partiendo de un panorama de Santa Tecla en esos años, presenta algunos testimonios orales acerca del tema, poniendo en relieve algunas características: la obligatoriedad de la educación, la participación de las niñas, la preocupación gubernamental por la alimentación y la salubridad, los castigos y la salida laboral.
\end{abstract}

\section{Palabras claves}

Educación básica, historia oral, Santa Tecla, experiencias educativas.

\begin{abstract}
:
This work is an investigation from oral sources, and inquire about education in Santa Tecla, in the 1930s. From a picture of Santa Tecla in those years, presents some oral testimonies on the subject, highlighting some features: compulsory education, girls' participation, government concern for food and safety, and punishment labor output.
\end{abstract}

Keywords:

Basic education, oral history, Santa Tecla, experiences of schooling.

1. Historiador independiente. Profesor e investigador salvadoreño. Email: carloscorteztejada@ gmail.com 


\section{Preámbulo}

El siguiente es un trabajo que intenta dar un somero acercamiento hacia la educación básica salvadoreña durante los años de 1930. Se trata de un esfuerzo en curso de rescate de memoria por medio de la historia oral. Esta consiste en la recopilación de relatos contados por los mismos protagonistas de esta parte de la historia que aún no se ha finalizado. Por lo mismo, en el presente texto se expone un caso específico de los recopilados, debido a que aún no existe un análisis global de todos en su conjunto.

Es importante destacar que en historia oral es esencial hacer hablar a las mismas personas que han producido las fuentes históricas. Por ello se observará a la fuente oral y al investigador hablar aleatoriamente con el afán de poner al lector en contacto directo con las ventanas que los protagonistas se disponen abrir para hacer una interpretación de ese momento histórico en El Salvador.

\section{La educación básica en Santa Tecla, El Salvador durante la década de 1930}

Con frecuencia se escucha en la actualidad, de parte de las generaciones envejecidas, que todo lo de su época era mejor que lo de hoy día. La música era más honesta, las modas eran más formales, la gente poseía mejores modales y valores, entre otras. Igualmente pasa con el ámbito de la educación. Es usual escuchar a personas ancianas que la educación de su tiempo era mejor que la actual porque inculcaban valores y en suma enseñaban más antes que en las escuelas de hoy.

El presente trabajo pretende hacer un acercamiento breve a través de una minúscula ventana hacia el pasado sobre la educación salvadoreña de hace casi ya ochenta años atrás. El tema a presentar, como ya se sabe es la educación básica en Santa Tecla, La Libertad, El Salvador durante la década de 1930. El problema a tratar específicamente dentro de este tema son las experiencias de escolarización en la mencionada ciudad durante los años de 1930. Para ello se recurrió a relatos orales de personas que vivieron en dicha localidad y asistieron a la escuela más o menos durante esta década. En concreto se utilizaron los relatos de Adelita Palacios para la realización de este ensayo y otras fuentes secundarias (ver bibliografía) que dieron algún soporte teórico a sus testimonios.

\section{Santa Tecla en la década de 1930}

Santa Tecla hacia la década de 1930 era como un pequeño pueblo, separada de la ciudad capital salvadoreña, a diferencia de hoy en día. Su casco urbano era muy reducido, limitándose exclusivamente a los barrios que se orientaban alrededor de las dos plazas principales de la ciudad, el Parque Daniel Hernández y el Parque San Martín. Sus calles eran todas empedradas. Las banquetas por donde transitaban los transeúntes eran generalmente de tierra, con excepción de las partes céntricas y frente a los edificios consistoriales, así como frente a las casas de las clases altas, en donde se colocaban unas lajas -unas piedras naturalmente 
lisas, planas, largas y de poco grosor-; esto debido a que al parecer no existía una preocupación por parte de la municipalidad para pavimentar las aceras, este hecho se explicaría debido a que el tránsito de automotores por las calles era escaso, ya que el transporte de la época se hacía más que todo a caballo, en carreta o sencillamente a pie. Aquella situación obligaba a que cada familia acaudalada se diera a la tarea de colocar estas lajas frente a su hogar; lujo que las clases bajas no podían darse. Frente a las casas del resto de la población, lo único que se hacía era colocar unas tablas que conducían hasta el empedrado de las calles durante la época lluviosa para evitar enlodarse los pies. ${ }^{2}$

"Las calles eran empedradas y para pasarse de un andén a otro, que no había andén como ahora, eran unas lajas que hacían las veces de un andén. La casa que tenía para mandar a poner las lajas, laja es piedra, lo ponían y la que no, pues pasábamos sobre la tierra. Cuando llovía se ponían unos puentes de madera, no sé en qué fecha empezaron a pavimentar, pero así era". ${ }^{3}$

La ciudad estaba rodeada por completo de cafetales, el café era la dinamización económica de Santa Tecla. Su población se dedicaba, en temporada, a las cortas de café en las fincas circunvecinas. Cuando pasaba la época de corta, las actividades de subsistencia se transformaban al comercio informal y la agricultura de otros granos básicos.

"Se llamaba 'la Ciudad de las Colinas', es posible que fuera ciudad de Santa Tecla, pero era muy pequeño. Le rodeaban cafetales, árboles frutales, había muchos animalitos de diferentes clases y colores... Lo que ahora se dice Residencial San Luis (San Salvador), Paseo El Cafetalón, Residencial Las delicias, Residencial Betania, esos eran cafetales llenos de árboles frutales como dije antes que se escuchaban muchos pajaritos de todos colores y e diferentes razas (especies)... Todo lo que es El Cafetalón eso eran fincas, porque la finca se llamaba El Cafetalón, porque era grande". ${ }^{4}$

Pero la principal fuente de ingresos, según parece, era la caficultura. La población tecleña miraba en esto su principal modo de subsistencia debido a que era, a su parecer, la mayor fuente de recursos monetarios como ninguna otra. Así lo confirma el testimonio de Palacios:

“Había un bus que decía 'El Volcán' y cuando había cortas de café, eso era precioso. Fíjese que en la mañana tenían que hacer todo lo que los cafetaleros tenían que hacer para llevar gente a la corta de café.

2. Adelita Palacios. 16 de junio de 2013, Soyapango, San Salvador. Carlos Ernesto Cortez Tejada.

3. Ibíd.

4. Ibíd. 
A eso íbamos con mi abuelita y mi tío Salvador. ¡Eso era precioso ir! Porque uno no gastaba en comida porque todo había, le daban a uno dos tortillas de este porte (hace la muestra con sus manos colocando los dedos índice y pulgar de sus dos manos en forma de media luna, semejando con ambas un círculo pero sin juntarlas), un cumbo de frijoles, un puño de sal, ése era el almuerzo. Las mujeres cocinaban para llevar, para comer, llevaban queso y todo y le daban a uno una ficha a la hora en que iba el caporal, en eso anduve también, anduve cortando con ellos y me gustaba mucho, me encantaba, y traía una fruta, leña y cada quien con su racimo de leña; las mujeres en la cabeza con su canasto; a mí me hacían un manojo chiquito de leña y lo traía en la cabeza y mi mamá en el canasto traía todas las frutas que había recogido y mi abuelita también. Decían que se ganaba, porque todo era barato. Los huevos eran a tres centavos de colón, la azúcar valía nueve centavos la libra, la sal, la libra, valía un centavo. Era diferente para el asunto de la alimentación por eso la gente sentía que ganaba, no porque la arroba de café en uva ya limpio, lo pagaban a cincuenta centavos de colón. Así es que un hombre si se cortaba ocho arrobas había ganado cuatro colones, jah!, jera un pistal para él!... Venían camiones a traer gente para 'La Cumbre', así se decía. Allá le iban a dar a uno cama, le iban a dar alimentación y le iban a dar donde dormir, pero donde dormir eran unas galeras". ${ }^{5}$

Al terminar el período de cosecha de café, la población buscaba ingresos de la manufactura y del comercio informal.

Las viviendas eran por lo general de adobe o bahareque, con tejas a dos aguas, repelladas con cal. Al alejarse del casco urbano de Santa Tecla, las casas se diseminaban por las fincas de café hasta llegar a las casas de los colonos en las mismas fincas.

"La casa de nosotros era de adobe y con cal la pintaban. Dentro de ella... una cocina grande al lado de afuera, por un corredor; y adentro había un cuarto que daba para cuando salía uno en lo alto y veía que iban las carretas de bueyes y los caballos y allá 'onde 'onde un carro, un pick up, que eran los ricos que pasaban a ver sus cafetales, y de ahí para allá estaba donde dormían mi "papá" (padrastro) y mi mamá, otro donde dormía mi abuelita conmigo y mi hermanita, porque todavía no había nacido mi hermano". ${ }^{6}$

Así era como transcurría la vida cotidiana en este pequeño núcleo urbano salvadoreño, enclavado entre cafetales, en una suave e inclinada llanura,

5. Ibíd.

6. Ibíd. 
prolongación fina y agradable de la ladera sureña del Volcán de San Salvador.

Para abrir una minúscula ventana hacia las experiencias de escolarización en este pequeño enclave urbano durante los años de 1930 se ha tratado de documentar las vivencias de Adelita Palacios, una señora de más de ochenta años, nacida según su partida de nacimiento en enero de 1929 y según su propia historia en diciembre de 1930 en el cantón Melara de la municipalidad de Rosario de Mora, departamento de San Salvador. Desde que tuvo pocos días de nacida fue llevada por su familia a Santa Tecla, donde vivió toda su niñez hasta la edad de quince años, aproximadamente. Acá cursó ella cinco de los seis grados que estudió, lo que se conoce como educación básica.

\section{Educación básica de Adelita Palacios}

Adelita Palacios es hija de Leonor Palacios (1906-1986) y Carlos Enrique Valle(1904-¿?). Se crio con su madre; el hermano de su madre, Salvador Palacios (1910-2011); y la madre de estos, María Jesús Palacios (1888-1940). Posiblemente se radicaron en Santa Tecla por la caficultura, que era la principal dinamizadora de la economía salvadoreña en aquella época. Como se ha visto antes, esta familia se dedicaba especialmente a las cortas de café, la agricultura y el comercio informal.

A pesar que la madre de Adelita Palacios y su tío podían leer y escribir, mas no su abuela, María Palacios, no existía una preocupación por la educación básica de aquella, al menos en cuanto a enviarla a la escuela se refiere; no sólo porque Adelita ayudara desde muy temprana edad a la economía familiar, sino porque su tío le dio la educación de las primeras letras en casa. ${ }^{7}$

"Me tocaba andar en las tiendas avisando que si iban a querer lo que mi mamá producía con mi abuelita. Ellas hacían tamales pisques, hacían tamales de elote, hacían fritadas, chicharrones, cigarros que se llamaban patecuña porque se envolvía el cigarrito así (muestra con sus manos la forma en que se hacía) se le echaba el tabaco y si hacía el cigarrito (muestra con sus manos la forma en que se enrollaba) y después, con un palo de fósforo lo puyaban así, por eso se llamaba patecabra o patecuña, los dos nombres. El manojito valía cuartillo que eran tres centavos salvadoreños (colón) y vendían seis cigarros. Ya los puros, según el tamaño así era el valor de los puros, porque en ese tiempo estaba la cigarrería para los ricos que fumaban cigarros finos, me acuerdo de una marca allá a lo lejos... no me acuerdo muy bien, pero si existía, nosotros decíamos 'los cigarros de viejo choco' porque era un embajador que tenía un cigarro con un anteojo, esos eran los señores que fumaban en pipa, pero los pobres fumaban puros y ese cigarro (el descrito al principio) que era lo que producía mi familia. Íbamos a

7. Ibíd. 
traer leña a los cafetales, varios muchachitos (iban). Mi tío-papá tenía una carreta con una yunta de bueyes, dos caballos. Mi mamá criaba tuncos, gallinas. Teníamos qué comer, pero... al morir mi abuelita ya no fue igual (dice con mucha tristeza y nostalgia, casi llorando)". ${ }^{8}$

Puede observarse acá, pues, que Adelita Palacios se dedicaba a realizar mandados de su familia para ayudar a la economía familiar antes de ingresar a la escuela. No obstante, ocurriría algo nesperado en su niñez, que cambiaría su infancia para siempre. A pesar de no existir intenciones de su familia para asistir a la escuela, ni ella tener tampoco intenciones de ingresar a estudios básicos, un policía la detendría mientras se dirigía a realizar un mandado familiar quien le mandaría a la escuela, no sin antes hablar con su familia.

"Yo no fui a la escuela cuando tenía seis años, no existía la preparatoria, habian escuelitas privadas en las iglesias en donde las personas que daban doctrina (catequistas) enseñaban, pero yo aprendí a leer, a escribir y a sumar por mi tío-papá. Nadie me había llevado a matricular ni nada, yo no conocía la escuela, pero sí un día venía de hacer un mandado de la casa y me encontró la policía, pero en aquel entonces quizá la policía no eran como los de ahora, él (el policía) me detuvo, no les tenía miedo uno. En esa época, cuando el policía me detuvo había cumplido los siete años. Me dijo que de dónde venía, y ya le dije que de hacerle el mandado a mi abuelita y a mi mamá. Y me dijo: ‘Y vas a la escuela?’ No -le dije yo-. ‘¿Nunca has ido a la escuela?’ No. ‘No te han llevado a matricular?’ No. Entonces me dijo: 'Vamos a ir a tu casa'. Como era cerquita, todo reunido, ya lueguito llegamos a la casa, como nosotros vivíamos... El policía llegó hasta mi casa, por supuesto, se afligieron al ver que yo iba con el agente, ya salieron a ver qué pasaba. Y les dijo el agente: 'No, no se preocupe, andamos viendo de que mañana, a usted le entrego este papelito, para que se presente a la Escuela Pilar Velásquez' que era a escuela de niñas, no había otra. Daniel Hernández para varones y la Escuela Pilar Velásquez para las niñas. Así quedó. Otro día me vinieron a matricular. Yo no conocía qué era un pizarrón, qué era un bolsón, qué era un pupitre, no. No es que en mi casa no hubiera muebles, pero a una escuela no había entrado, no sabía que se llamaban aulas, grados, ni nada de eso". 9

Este hecho coincide con el hecho de las disposiciones del gobierno del General Maximiliano Hernández Martínez, que toda la educación primaria era una obligación para todos los ciudadanos y debía ser al mismo tiempo gratuita. ${ }^{10}$

8. Ibíd.

9. Ibíd.

10. José Alejandro Sosa Cortez, "Historia de la educación en El Salvador, 1919-1992. Los sistemas educativo y socio-económico, una pareja de evolución dispareja" en Memoria Primer Encuentro de 
La familia de Adelita Palacios no se hizo esperar y fueron a inscribirla a la escuela, según la orden que les había dado el agente policiaco:

"Luego, el día que me fueron a matricular, supongo yo, sería lunes. Pienso que a mi mamá le han de haber hecho muchas preguntas. Ya luego me dijeron, venga mañana, que se le va a tomar medida para el uniforme y los zapatos. En aquella época, los padres... así como estamos ahora, así como ahora hecho el presidente que está y el FMLN, que están dando los cuadernos, los zapatos, el uniforme; así fue en esa época, fue lo bueno que tuvo el General Martínez. Él fue un presidente, que así como fue cruel, así tuvo sus partes nobles y buenas. Y otro día llegamos, me tomaron medida y me dieron rapidito el uniforme con los zapatos. Pero el primer día que me presenté andaba con mis zapatillos normal, chiquitillos y mi vestido, con trenzas. Me dijeron: 'Sólo traiga agua' porque en la escuela no había agua, Entonces yo con mi, antes no existía el plástico, pichinguita de barro y los varones llevaban tecomates a la escuela de varones. Ya con mi pinghinguita de agua que llegué y dijeron que ahí daban comida, que no fuéramos a llevar. Ya otro día me asusté yo cuando llegué que bien bonitas las mesitas". ${ }^{11}$

Claramente es notorio que existía todo un programa educativo en alguna medida integral durante estos años, ya que no sólo los policías tenían la orden, según parece, de introducir a todo infante que anduviera en la calle, sino que también el material didáctico, uniformes y zapatos corrían por cuenta del Estado.

En cuanto a lo que impartían en las clases, Adelita Palacios lo expresa de la siguiente forma:

"La señorita (profesora) se llamaba Carmencita, del apellido no me acuerdo. Ahí fue a conocer el yeso, no había visto una barrita de yeso. Ya puso las letras ella: $A-B-C$... todo lo de primer grado. Cuando me tocó mi turno que me parara a decir, le dije: 'Eso, señorita, yo se lo puedo decir de memoria con los ojos cerrados'. Quedó sorprendida la maestra. Entonces me dijo: ‘Cómo es que puedes el abecedario?’ Me lo han enseñado en la casa, me lo ha enseñado mi tío-papá. 'Dilo' -me dijo, y lo dije. Continuó la clase, todo lo que estaban poniendo, después del abecedario, cuando ponían así se escribe mamá y todo eso yo ya me lo podía. Me dijo (la maestra): 'Mire, váyase para afuera y va a leer este libro, en lo que yo termino la clase'. Daba a entender que como yo decía dice así, dice asá, estaba interrumpiendo a los otros alumnos que

Historia de El Salvador: 22-25 julio, 2003, ed. Licenciatura en Historia (San Salvador: Dirección de Publicaciones e Impresos, 2005), 198.

11. Adelita Palacios. 16 de junio de 2013, Soyapango, San Salvador. Carlos Ernesto Cortez Tejada. 
no podían, era lógico. Entonces la señorita me prestó un libro para que yo me fuera a leer afuera, de muñequitos. Ya me fui afuera a ver los muñequitos y me dijo que los coloreara. No lo tomé a mal. Luego llegó la directora, ella se llamaba Zoila, ahí no habían hombres, me dijo: ‘¿Tú puedes leer?’ Un poquito, le dije. 'Toma aquí, léeme en este libro’-me dijo-. ‘Por qué no lees los principios?’ -me dijo-, 'Porque esos me los puedo de memoria' -le dije-, 'yo voy a leer todo lo de abajo'; como había que decir así: 'C $-A$ : ca, $S$ - A: sa = casa. Rrrrrrr R-O: ro, S-A: sa = rosa', así le enseñaban a uno Carlitos. ¿Y por qué iba estar haciéndolo, pues, si ya yo me lo podía? Raza-cosa-pino-lima... eso lo estaba leyendo. 'Vamos a ver' -me dijo, ‘y con los números? ¿Hasta dónde puedes?’ Hasta el cien. ‘Me lo puedes decir?’ Se los dije. Ya cuando iba por el 80... (con sonidos jadeantes) 81..., 82... 'Ya, hasta ahí. Ya se sabe que los puedes'-me dijo la niña Carmencita y la niña Zoila, que era la directora-. Ahora dime: ‘Puedes sumar? ¿Qué es para ti sumar?' Hacer comparación de un número con otro, luego los sumo, a ver cuánto me da (le dijo), porque yo cuando voy a dejar los puros y los cigarros de mi abuelita, ella me dice y me explica cómo debo de saber. Si me van a pagar cuatro reales de cigarros y cuatro reales de puros, ya está un peso. Me dijo: 'Hazlo aquí', ya me puso una suma como... del 2, yo ya... de chiripa para mí. 'Está bien, está bien' -me dijo-”. ${ }^{12}$

A pesar que este relato demuestra una vivencia muy particular en el caso de Adelita Palacios, deja entre ver cuál era el tipo de educación que se impartía en los primeros años. Pero esto no era lo único que se hacía, según cuenta Palacios, se impartían las cuatro materias tradicionales de la educación salvadoreña: Lenguaje y Literatura, Ciencias Naturales, Estudios Sociales y Matemáticas, pero además de eso, a las niñas les impartían una materia más que se relacionaba a las manualidades y aspectos hogareños:

"Pero después de esas cuatro..., ahora le dicen manualidades, no recuerdo que en ese tiempo le dijeran así, le enseñaban a uno a coser, a bordar, a pegar botones, a remendar, nos enseñaban a hacer delantales de manta, nos pusieron a aprender a hacer sombreros, cuando uno se hacía una herida con qué se podía curar, que decían que eran primero auxilios". ${ }^{13}$

Con esto era claro que la educación de las niñas se orientaba, en alguna medida, en forjarlas como amas de casa, como madres de familia para que atendieran a sus hijos y a su esposo. Esto hace notar la influencia que la mentalidad tradicional tenía sobre la educación salvadoreña, incluyendo las formas de castigar que imperaban en las escuelas en esa época: 
"Fue muy bonito (la experiencia escolar), las profesoras eran ingratas, pero se aprendía, porque tenían una regla (para castigar). A mí muchas veces me pusieron en el sol porque peleaba por una cuerda para saltar cuerda y me molestaban con mi nombre y no me gustaba y quería que me respetaran porque yo no las molestaba y me castigaban; me ponían en el sol o me pegaban con una regla. Una vez me quitaron el lazo -la señorita- y ya no me lo volvió a dar, era mío el lazo pero las muchachitas peleaban por el lazo". ${ }^{14}$

Por otra parte, puede notarse una política estatal en las escuelas en cuanto a alimentación y salubridad se refiere:

"Para comer en la escuela, cuando nos daban el arroz en leche cosas así que daban: 'Hoy no van a ocupar las cucharas de morro, sino que van a ocupar cucharas de metal'. Ahí es donde yo conocí lo que era metal, en la casa no había cucharas de metal. Por si a una niña se le caía o algo, en el primer grado habían unas cucharitas de morro, bien blanquitas. Cada quien lavaba la cucharita y la iba a guardar en un cajón. A la mía ya le habían puesto el nombre. Cada quien ya reconocía su cuchara de morro y un guacalito de morro para comer. Entonces dijeron que habían donado cucharas de metal, ahí ya conocí qué era metal. Otra cosa, existía el TDT, la que llegaba con piojos ahí se los sacaban. Había unos galones, igalones! (enfatiza), porque no existía el plástico, unos galones llenos de agua... Ahí le daban también para sacarle las lombrices (parásitos) a uno, le daban aceite de pazote, de veras Carlitos. Quizá para desparasitar. $Y$ como es horrible el aceite de pazote, es amargo entonces se lo daban entre dos profesoras, una le metía una cosa como que era concha aquí a uno (hace la muestra con su mano y su boca) y la otra le empujaba el aceite y ya después le daban un pedacito de limón con sal para que lo tragara uno. Otro día uno no iba a la escuela por la currutaca, amanecía enfermo del estómago (ríe). La que tenía lumbrices le salían y la que no, no. Para eso era, yo pienso que era para desparasitar, eso existía en aquel entonces. Botiquín, había también, había agua oxigenada, un mercurio, algodón, aspirinas por un catarro. Por si uno se caía le echaban agua oxigenada y mercurio cromo se llamaba el rojo". ${ }^{15}$

Claramente estas son políticas de Estado en cuanto a salubridad y alimentación de la población infantil se refiere.

\section{Apreciaciones finales}

La educación básica hacia la década de 1930 es ya una preocupación para el Estado, al grado de convertirla en una obligación para la población, aspecto 
que llevó al gobierno a recurrir a las autoridades policiacas para recoger a niños que no estuvieran en la escuela. Igualmente fue preocupación estatal la alimentación de la niñez y la salubridad de esta, al punto de implementar medidas dentro de las escuelas que velaban por estos aspectos. Además de esto, el material didáctico y los uniformes eran asuntos que proporcionaba el mismo gobierno.

Las niñas ya eran tomadas en cuenta dentro de la educación al existir escuelas para el sexo femenino, no obstante, la educación para estas era aún orientada hacia los aspectos hogareños. Sin embargo, la educación podría decirse que era integral de alguna forma, ya que además de asuntos como la costura, también se daban clases de las materias tradicionales de la educación salvadoreña. La escuela era influenciada por la mentalidad de la época, ya que los castigos severos y maltratos estaban presentes como una manera de "educar" a los estudiantes.

En otro aspecto, es notorio que desde hace mucho el trabajo infantil ha estado presente en la sociedad salvadoreña. Los niños desde hace décadas siguen figurando como una pieza más dentro de la generación de recursos económicos para las familias salvadoreñas, sacrificando con eso su educación.

\section{Bibliografía}

Adelita Palacios. 16 de junio de 2013, Soyapango, San Salvador. Carlos Ernesto Cortez Tejada.

Gal, Roger. Historia de la educación. Buenos Aires: Paidós, 1968.

Sosa Cortez, José Alejandro. "Historia de la educación en El Salvador, 1919-1992. Los sistemas educativo y socio-económico, una pareja de evolución dispareja”. En Memoria Primer Encuentro de Historia de El Salvador: 22-25 julio, 2003, editado por la Licenciatura en Historia, 193-205. San Salvador: Dirección de Publicaciones e Impresos, 2005.

Trejo de Palencia, Etelvina. Historia de la Educación Parvularia en El Salvador. San Salvador: Universidad Pedagógica de El Salvador, 2012. 